OPEN ACCESS

Edited by:

Parul Rishi,

Indian Institute of Fores

Management, India

Reviewed by:

Irene Chu,

Bradford University School of Management, United Kingdom

Gregory Beabout,

Saint Louis University, United States

${ }^{*}$ Correspondence:

Caleb Bernacchio

cbernacchio@csumb.edu

Specialty section: This article was submitted to

Organizational Psychology,

a section of the journal

Frontiers in Communication

Received: 07 June 2021

Accepted: 24 January 2022

Published: 28 February 2022

Citation:

Bernacchio C (2022) Does

Maclntyre's Moral Sociology

Presuppose a Personalist Moral

Psychology? Maclntyre and Tomasello

on Moral Psychology.

Front. Commun. 7:721759.

doi: $10.3389 / f c o m m .2022 .721759$

\section{Does Maclntyre's Moral Sociology Presuppose a Personalist Moral Psychology? Maclntyre and Tomasello on Moral Psychology}

\author{
Caleb Bernacchio ${ }^{1,2 *}$ \\ ${ }^{1}$ College of Business, Fordham University, New York City, NY, United States, ${ }^{2}$ California State University, Monterey Bay, \\ Seaside, CA, United States
}

Alasdair Maclntyre has developed a theory of virtue ethics that is closely integrated with sociology and organization studies. While rejecting reductive views of the virtues, Maclntyre appeals to their functional role in facilitating collaboration as a basis for justifying their normative requirements. This raises the question of how agents within cooperative contexts come to appreciate their intrinsic value. I argue that Maclntyre's account of the virtues is undergirded by an implicit personalist moral psychology. To make this evident, I draw upon the account of moral psychology developed by Michael Tomasello, who argues that a sense of moral obligation is generated when persons engage in collective action. Tomasello's account complements Maclntyre's by explaining how participation in social practices generates a sense of moral obligation but it does not address the problem of relativism. As a result, it does not fully explain how and why participants in practices come to see themselves as bound by moral norms since the threat of relativism undermines the idea that moral norms are binding. This limitation further illustrates the role of a personalist moral psychology in Maclntyre's work: through the experience of cultural breakdown persons are able to view themselves as engaged in a shared inquiry concerning the good that transcends any specific culture. This provides the basis for a self-conscious sense of moral obligation that is not threatened by relativism.

Keywords: virtue, personalism, joint intention, moral psychology, relativism

\section{INTRODUCTION}

In the span of roughly 40 years, interest in virtue ethics, especially in its neo-Aristotelian form, has grown dramatically in moral philosophy (Hursthouse, 1999), business ethics (Moore, 2017), and organization studies (Tsoukas, 2018), amongst a number of other areas in the social sciences and applied ethics. Alasdair MacIntyre's After Virtue (2007) both provided a major impetus to this movement and contributed a novel account of the virtues centered upon their functional role in sustaining social practices. By integrating virtue ethics with practice theory, MacIntyre (2007) introduced a novel grounding for the virtues: Virtues are not only valuable for their own sakes (McDowell, 1978, 1980) but also because they sustain and promote excellence within contexts of collaborative activity, that is, social practices. For MacIntyre, social practices include such activities as sports, games, academic disciplines, the arts, and various crafts and modes of production, as well 
as participatory politics, homemaking, and community organizing. In organization studies, a wide range of organizations (Moore, 2012) and professions (West, 2018) have been conceptualized as practices, including management (Holt, 2006; Beabout, 2012). Within these cooperative contexts, the virtues function to preserve participants' commitments to the standards of excellence and shared goals that are constitutive of the practice.

However, MacIntyre's novel approach to the virtues, where their necessity stems from their role in supporting and sustaining excellence within practices, raises a more fundamental question about how agents come to appreciate the intrinsic value of the virtues. Why is this important? First, without an intrinsic commitment or sense of obligation, the virtues are unlikely to be effective in sustaining cooperation (Adams, 2006) since agents are likely to freeride when this is to their advantage (Rawls, 1958). Second, a purely functional or instrumental notion of virtue does not capture the Aristotelian notion of virtue as a mode of moral excellence (McDowell, 1978, 1980). In effect, such a construal of virtue changes the subject rather than articulating what it is that makes virtue truly choiceworthy (Korsgaard, 1986).

To address this problem, I argue that MacIntyre's moral sociology presupposes a distinctive moral psychology, an account of what is that agents must think in order to think rightly about the role of the virtues in their social practices (Anscombe, 1958). MacIntyre's (1999) account centers upon the notion of "political recognition" (1999: 141), the attitude whereby human beings are capable of viewing others as fellow partners in a shared inquiry concerning the good; and, therefore, as someone from whom it is possible to learn from. From this perspective, virtues function to sustain practices only because the goods internal to practices are subsumed within a broader notion of the good, the good of life as a whole (MacIntyre, 2007), and participation in practices is seen in the light of the broader activity of moral inquiry. In this context, the virtues play a constitutive role in facilitating inquiry in common with others. And because the scope of practical inquiry is unlimited, such that one may learn about the good from anyone in any context (MacIntyre, 1999), the virtues are universally binding.

To explain MacIntyre's approach, I first outline Tomasello's (2020) account of moral psychology. Tomasello seeks to provide a non-reductive account of moral obligation, where agents, who come to identify with the group of which they are a part, selfconsciously bind themselves by the norms current within their group. While Tomasello's account of moral obligation as based in group agency offers important insights for understanding MacIntyre's account of moral psychology, it is inadequate on its own because it faces the problem of relativism: if moral obligations are grounded in joint agency, as Tomasello (2020) argues, then moral obligation is relative to groups of agents engaged in such projects, for instance, members of specific cultures. As a result, Tomasello (2020) fails to provide a nonreductive account of moral obligation, an account that explains how individuals can come to view moral norms as binding rather than arbitrary. This is the case since individuals who come to appreciate Tomasello's account are likely to view their sense of moral obligation as arbitrary and culturally relative, giving them reason to dismiss this sense of obligation as meaningless.

Exploring the shortcomings of Tomasello's account provides further insights into MacIntyre's personalist moral psychology. MacIntyre (1985) overcomes the problem of relativism by appeal to the notion of intellectual failure or epistemological crisis within shared inquiry. It is the experience of actual or potential failure in moral inquiry that overcomes cultural boundaries, teaching participants that the good can never be reduced to any given culture's conception of it. This underwrites a corresponding notion of political recognition as universal in scope, founded upon the idea that it is always possible to learn from others about the good (MacIntyre, 1994). In this sense, a personalist moral psychology underwrites MacIntyre's (2007) functionalist account of the role of virtues within practices, since persons achieve their good only by viewing themselves as engaged in shared moral inquiry with other persons. Tomasello's (2020) account is important both because it shows the role of joint agency in generating a sense of moral obligation and because its failure to solve the problem of relativism indicates that the notion of moral obligation presupposes some form of joint agency that is not culturally specific; and as MacIntyre $(1985,1994)$ makes evident, this mode of collective action is moral inquiry.

\section{MACINTYRE ON VIRTUE WITHIN PRACTICES}

In the early portions of the 20th Century, much influential work within moral philosophy, ignored the distinct approach to ethics characteristic of virtue ethics, focusing instead on various "modern moral theories", including especially forms of consequentialism and deontology (Anscombe, 1958). In After Virtue (2007), MacIntyre argued that modern moral theories are inadequate because they ignore the question of the telos of human life or the human good as an essential basis for ethical norms. While it is not possible to recount these criticisms at length, in brief, MacIntyre argued that deontological norms are arbitrary and vacuous without some account of the goal that they promote. What is needed, for example, is some account of why the sort of life that is lived in accordance with the Categorical Imperative (Kant, 2012) is a valuable life. Consequentialist theories, especially Utilitarianism, are similarly problematic because they do not give an adequate account of the telos of human life. These theories often adopt a monistic notion of value, where life is focused on maximizing one type of good, often pleasure; but this monism is inadequate to account for the varied goods needed to live a flourishing life. Accordingly, MacIntyre (2007) develops a neo-Aristotelian approach to virtue ethics that aims to avoid the shortcomings of modern moral theories. He focuses on the way that virtues enable individuals within concrete social contexts to identify and achieve the varied goods that contribute to human flourishing.

Thus, MacIntyre's novel contribution to virtue ethics centers upon his account of the role of the virtues in sustaining social practices. Practices provide concrete social contexts, where the goods that constitute flourishing are identified and articulated 
over time. He says, "so long as we share the standards and purposes characteristic of practices, we define our relationship to each other...by reference to standards of truthfulness and trust, so we define them too by reference to standards of justice and of courage" (see MacIntyre, 2007, p. 192; Beadle, 2013). That is, within practices participants must relate to each other in terms of the virtues, if not, they will, in effect, no longer be participating in the practice. The rules structuring practices are constitutive norms (Rawls, 1955; MacIntyre, 2007, p. 187), such that following these norms is a necessary condition to "count" as actually engaging in the practice. If someone who is ostensibly a chess player squares up to an opponent but soon begins moving his rooks diagonally, his bishops linearly, and his pawns laterally, he is no longer playing chess. Less dramatically, someone who cheats, being untruthful about the movements of his pieces and unfair to his opponent is only playing chess in a marginal sense. The case is similar for a cowardly opponent who is unwilling to insist that the cheater follow rules. While they may be sitting in front of a chessboard moving pieces around the board, these "players" are not really playing chess. They have sufficiently failed to adhere to the norms that are constitutive of the game such that we cannot "count" them as actually playing the game.

For scholars in applied ethics (Sellman, 2000), including especially business ethics (Beadle, 2017; Sinnicks, 2019), and organization studies (Moore, 2012; Tsoukas, 2018) this account of the role of the virtues within practices opened up new possibilities for research. Specifically, it allowed for the integration of practice theory (Sandberg and Tsoukas, 2011) and ethical analysis, facilitating both empirical research concerning the role of virtues within professions and organizations (Robson, 2015; West, 2018) and novel theoretical frameworks (Moore, 2017; Bernacchio, 2018) supporting this work. But despite the fecundity of this development, very little work has directly examined the question of how participants in practices actually come to appreciate the intrinsic value of the virtues (see Weaver, 2006). Appeals to socialization (Bernacchio, 2019) and imitation (Shotter and Tsoukas, 2014) go some way in this direction but they do not unfold the moral psychology underlying practice members' virtuous agency (Anscombe, 1958).

MacIntyre (2007, p. 264) says "The importance therefore for beginning from practices in any consideration of the virtues is that the exercise of the virtues is not only worthwhile for its own sake-it turns out that you cannot be genuinely courageous or just or whatever without caring for those virtues for their own sake-but has further point and purpose, and indeed that it is in grasping that point and purpose that we characteristically initially came to value the virtues." In other words, within practices, moral agency is "situated," so that it is possible to understand participants' moral agency in a moral realistic manner, as focused both on acting for duty's sake and in order to achieve the aims characteristic of the practice, these latter providing the "further point and purpose," motivating agents to cultivate the virtues. But a relevant question is what is it that virtuous practitioners come to appreciate when they come to care about the virtues for their own sakes.

I argue below that what these virtuous individuals come to see is that the virtues necessarily define the way that persons ought to relate to other persons, insofar as they view each other as someone that it is possible to learn from, as fellow pilgrims on a narrative quest in search of the good (see MacIntyre, 2007). In this sense, a personalist moral psychology underwrites MacIntyre's moral sociology. But it is firstly important to appreciate the rather limited role that the virtues actually play in sustaining practices. There are two points to consider. First, as MacIntyre (2007, p. 187) argues the standards structuring practices are constitutive norms, such that one cannot participate in a practice without adhering to these norms. Given this, in a real sense, one cannot even play chess, much less achieve excellence in the game, while cheating. This means chess players must be honest enough to avoid cheating even if it cannot be detected. Likewise, players must be just or fair enough to refrain from contesting the legitimate moves made by other players. They must not, for instance, argue that a player had taken her hand off of a piece when she had not done so. But it is important to note that players would not necessarily need to be honest or fair when dealing with players in closely related contexts outside of the actual context of a chess match. Players may still engage in the game of chess while, for example, lying to fellow players when they ask questions about moves made in a previously completed match. Similarly, players may be unjust or unkind when dealing with fellow players outside of the match. For instance, they may refuse to help out fellow players who ask for assistance in improving their playing abilities. Acting unvirtuously in these ways would not mean that these players are violating the constitutive norms of the game of chess. That is, it would not mean that these players are failing to actually play the game of chess. Thus, there is a very limited role for the virtues in actually sustaining practices. Arguably, this role fails to capture the ideal of excellence typically associated with the notion of virtue (McDowell, 1980; Adams, 2006).

Second, as MacIntyre (2007, p. 194) argues some degree of virtue is required if participants are to achieve excellence within specific practices. Again, because the standards of excellence characterizing practices are constitutive norms, one cannot be an excellent practitioner while violating those norms. One cannot be an excellent chess player while cheating. But this argument presumes that players care about excellence rather than winning. But this need not be the case. Participants may engage in the practice for an extended period of time while pursuing success rather than excellence. Recently, an American football team was accused of cheating by using surveillance to gain insight into an opposing team's strategy. This is unethical and not directed toward excellence in the game of football but if undetected, it would likely enable the team to achieve a greater degree of success. In other words, participants need not be virtuous to engage in practices while pursuing success rather than excellence. One may criticize such persons for failing to fully appreciate the point of the game but it is not plausible to claim that they do not count as playing the game in any relevant sense. As such, why should a practitioner care about the virtues if she is primarily concerned about success as was the cheating football team (see Tenenbaum, 2019)?

MacIntyre (2007, p. 201) argues that the account of the role of the virtues within practices is merely an initial and 
partial account that presupposes a more robust conception of the good characterizing human life as a whole, that is, of human flourishing. Given the limited role of the virtues in actually sustaining practices, their importance for the moral life must involve an account of how participation in practices enables participants to grasp the relevant normative distinctions characterizing the virtues (McDowell, 1980). Thus, a necessary supplement to MacIntyre's account of the role of the virtues within practices is an account of the moral psychology required for virtuous agency (Anscombe, 1958), an account that explains the patterns of thought that make possible virtuous agency within practices.

\section{TOMASELLO ON JOINT INTENTIONALITY AND MORAL PSYCHOLOGY}

Tomasello (2020) offers a penetrating account of moral psychology that dovetails closely with MacIntyre's (2007) criticisms of modern moral philosophy and his account of the virtues as rooted in social practices. Tomasello $(2014,2016,2019)$ draws upon his previous research in evolutionary anthropology and developmental psychology, arguing that the experience of moral obligation is "first evident inside, but not outside, of collaborative activities structured by joint agency with a partner, and it is later evident in attitudes toward in-group, but not out-group, members connected by collective agency" (2020:1). Thus, like MacIntyre, Tomasello places great emphasis on joint agency, as the central locus of moral development. But he goes beyond MacIntyre's account in detailing the processes whereby participants in such activities develop a sense of the norms characterizing such activities as "binding" and intrinsically obligatory.

There are two salient aspects of moral obligation: The first concerns its special force. Moral obligation is experienced as negative and obligatory, demanding action (or inaction) against the agent's other desires. And the failure to observe salient moral norms is tied up with emotions such as guilt. As Tomasello (2020, p. 1) says, "Unlike the most basic human motivations, which are carrots, obligation is a stick." Second, moral obligation is typically linked with a distinct social structure, such that breaches of obligations often "prompt normative protest, from the offended party, and apologies, excuses, and justifications from the offender" (Tomasello, 2020, p. 1).

An influential tradition, rooted in the work of Hume and other Enlightenment philosophers, has attempted to explain moral obligation in second-personal terms (Strawson, 1962; Scanlon, 2000; Darwall, 2009). This tradition focuses on the role of other persons in holding individuals accountable and the necessary recognition that one must give to others if they are to fulfill this role. As such, one can only be a moral agent, being bound by moral norms and experiencing a sense of obligation, insofar as one recognizes others as having the authority to hold oneself accountable. Accordingly, from this perspective, one's sense of moral obligation stems from the internalization of the other's second-person stance. Despite its promising potential to explain some important features of moral psychology, it does not explain why persons care about blame coming from others, or more generally, what is involved when agents recognize others' reactive attitudes (Strawson, 1962) as legitimate.

Tomasello (2020, p. 6) addresses these limitations by drawing upon the notion of a "joint agent," a "we" that "not only conducts but also self-regulates the collaboration." Thus, it is human beings' distinctive (or unique) capacity for collective intentionality that explains the experience of moral obligation, the experience of being bound by norms and being responsible to specific others. These same experiences underwrite the role of the virtues within practices as noted by MacIntyre (2007, p. 192). As Tomasello (2020, p. 6) argues, by " 3 years of age, children are able to actually constitute a normatively structured joint agent 'we' by forming with a partner a joint commitment to jointly self-regulate the collaborative process." This distinct human capacity for joint agency, the ability to say "we," "gives each party to the agreement the standing to protest or rebuke noncooperative behavior" (Tomasello, 2020, p. 6). You can protest my shirking because we are collaborating. Thus, the formation of a group agent provides a basis for mutual recognition between participants, making the second-person protestations of participants legitimate. Each party recognizes the other as a fellow participant in the collaborative process, someone who is equally responsible for the achievement of shared goals. Since we are collaborating, I have responsibilities to you as a fellow participant.

Likewise, the joint agent, the "we", also allows for a form of self-conscious moral obligation. "The sense of obligation may thus be considered as a self-conscious motivation because it derives from a kind of threat from a 'we', into which one has entered, that one might lose one's cooperative or moral identity within that 'we'" (Tomasello, 2020, p. 12). I experience myself as bound by norms because I am involved in joint agency, that is, because we are collaborating. And these norms are recognized as self-consciously valid, or self-imposed because I am a constitutive member of the joint agent that we constitute. In a sense, we impose this obligation on ourselves. Thus, the distinct human capacity for joint agency grounds the experience of moral obligation and explains the standing that specific others have to hold fellow participants accountable.

It is worth briefly noting the important parallel between Tomasello's (2020) claims concerning the psychology of moral obligation and MacIntyre's (2007) well-known critique of modern moral philosophy. MacIntyre (2007) central claim was that moral norms-i.e., those typical of deontology, utilitarianism, and other modern moral theories-are unintelligible without reference to a concretely embodied notion of the good, especially that embodied within specific social practices (see Bernacchio, 2014). Within these contexts, moral norms are intelligible both as promoting causally and as constitutively realizing the morally salient goals embodied within specific practices (Taylor, 1994). Tomasello (2020) provides the moral psychological underpinnings of this account, explaining how joint agency in specific practices enables a "we" perspective, whereby participants hold themselves personally accountable from the perspective of the group agent. Thus, individuals can understand themselves as obligated by specific moral norms and responsible to specific others in terms of their shared participation in such a group 
agent. In other words, I am obligated because we are members of this practice and we must act this way in order to achieve our goals. Likewise, accounts of moral norms that leave out the context of joint intentionality make this type of normativity inexplicable (Tomasello, 2020).

Macintyre $(1988,1990)$ does not stop at the level of specific practices, focusing more broadly on cultural traditions as the bearer of complex conceptions of the good. Likewise, Tomasello (2020, p. 7) argues that specific cultures are the ultimate locus of moral obligation: "Cultural practices and social norms in large part identify our group as who we are: 'We' are those people who talk, think, dress, and eat in these particular ways". That is, specific cultures represent complex modes of joint agency, which shape participants' identities, providing the basis for their sense of moral obligation. This account provides much of the framework needed to understand MacIntyre's personalist moral psychology but it also suffers from a crucial limitation, a limitation that further serves to illustrate MacIntyre's account.

In short, according to Tomasello, moral obligation is relative to one's culture. He calls this a "self-conscious" sense of obligation (Tomasello, 2020) because agents bind themselves from the perspective of the group agent that they form with other members of their culture. But given Tomasello's account, moral obligation is necessarily reflectively unstable (Williams, 1985). That is, if participants in a specific culture come to understand why they experience a specific pattern of moral obligation in relation to specific persons, specifically if they understand their sense of moral obligation as a product of their arbitrary commitment to a given culture, this sense of obligation will become unstable (Williams, 1981). That is, they will have reason to reject these obligations as arbitrary products of their cultural formation, which are experienced as binding but that do not actually provide valid reasons to restrict their behavior accordingly.

Thus, Tomasello's (2020) account faces the problem of relativism: How can we think of ourselves as bound by moral norms if we understand moral obligation as a product of our participation in specific cultural practices. MacIntyre answers this question by appealing to a mode of joint agency that is not relative to a specific culture. By linking his account with Tomasello's analysis of moral obligation, key aspects of MacIntyre's personalist moral psychology become evident. It should also be noted that Tomasello and MacIntyre have different aims, where the former seeks to explain how the sense of moral obligation arises the latter is concerned to show that it is actually valid. As such there may be limits to the extent to which MacIntyre's solution to this problem, which I outline below, falls within the scope of Tomasello's inquiry.

\section{PERSONALISM}

Before explaining MacIntyre's response to this problem, a word about personalism is in order (see also Williams and Bengtsson, 2020). Maritain (1966: 12), the influential French Thomist and personalist, famously stated that "nothing can be more remote from the facts than the belief that 'personalism' is one school or one doctrine." Personalism, he argued, is instead a current of thought that responds to two problems that were particularly acute in the 20th Century: totalitarianism and individualism. Maritain (1966: 11) sums up these problems with the question, "Does society exist for each one of us, or does each one of us exist for society?" He notes that a "unilateral answer would only plunge us into error" (Maritain, 1966: 11). For Maritain (1966: 13) a "principal concern of Thomistic personalism is to avoid both excesses," thereby presenting an account of the person as neither a mere subordinate part of society nor an atomistic individual who is only accidentally related to others. Maritain (1966: 102) argues that the good of society must "flow back upon" persons, while persons must recognize that they "are subordinated to this common work [...] to be accomplished by the social whole as such," the common work of building a just society where persons can flourish. MacIntyre's response to the problem of relativism, which I refer to as his personalist moral psychology relates directly to the notion of personalism elaborated by Maritain.

For MacIntyre $(1999,2016)$, on the one hand, the internal goods of practices are good because they contribute to the good of the persons who participate in practices, that is, to their flourishing. On the other hand, persons live flourishing lives by contributing to the common good of the various practices and communities of which they are members. MacIntyre (1999, p. 109) says, that while "the pursuit of the common good of the community is, for all those capable of contributing to it, an essential ingredient of their individual good, the good of each particular individual is more than the common good." In this way, MacIntyre articulates the central premise of Thomistic personalism as elaborated by Maritain (1966). Thus, the personal and the interpersonal dimensions of human life are inherently linked, because persons live flourishing lives through their interpersonal relations with others.

Likewise, this conception of personalism relates specifically to the issue of moral psychology. Anscombe (1958, p. 5) famously argued that an adequate account of moral psychology, including "an account of what type of characteristic a virtue is," is needed to address the problems of ethics made apparent by the failures of modern moral theories. MacIntyre (1999, 2007, 2016) develops an account of moral psychology where the virtues both sustain practices and other forms of community and contribute to the flourishing of participants because they enable persons to learn from others person about the good. As he says, the virtues must "contribute to the good of that kind of whole human life in which the goods of particular practices are integrated into an overall pattern of goals which provides an answer to the question: 'What is the best kind of life for a human being like me to lead?' " (MacIntyre, 2007, p. 264). This provides a context for understanding the distinctive personalist moral psychology that undergirds MacIntyre's moral sociology.

\section{MACINTYRE'S PERSONALIST MORAL PSYCHOLOGY}

To this point, I have explained MacIntyre's (2007) distinctive contribution to moral philosophy and applied ethics in terms of his account of the role of virtues in sustaining social 
practices. This account offered new insights concerning moral education and new opportunities for research focused on specific professions and organizations as loci of such virtuous practices. But I have also argued that on its own this account is inadequate. It is inadequate because the ethical requirements necessary to "count" as participating in a practice (Rawls, 1955), while real, are minimal. One can engage in a practice as long one does not directly cheat by violating the rules structuring the activity, but one can do this while also harming fellow practitioners in a variety of other ways and while seeking success rather than excellence. This lacuna indicates the need for a more robust moral psychological account of the way in which participation in practices generates a genuine, non-instrumental commitment to the virtues amongst participants. Tomasello's (2020) account of joint agency as facilitating a self-conscious sense of moral obligation fills the lacuna in MacIntyre's account. It explains how participation in practices generates a notion of a group agent, a "we," whose dictates are experienced as binding on its members. In this way, the moral obligations that participants in specific practices experience stem from their membership in the group agent that is the practice.

This partially explains how participants in practices come to experience moral obligations within these contexts as categorically binding. But Tomasello's account is challenged by the problem of relativism since the recognition that one's sense of moral obligation stems from the arbitrary fact that one is a member of some specific culture rather than some other culture puts in question the validity of any moral obligations stemming from participation in that culture. Thus, his account does not fully explain how participants come to view moral obligations within practices as intrinsically valuable and binding. For how can one view oneself as bound by specific moral obligations if one is aware that these obligations would be completely different had one been raised in a different culture? MacIntyre addresses this problem in two ways, which together shape his personalist moral psychology.

First, whereas Tomasello's (2020) account focuses on the importance of culturally specific shared goals in generating a sense of moral obligation, MacIntyre (1985) argues that the experience of cultural failure is equally important to the development of a notion of moral objectivity. Cultural failure spans a spectrum from the radical breakdown experienced by some communities, such as the Crow Nation (Lear, 2006), whose way of life became obsolete as a result of social and ecological change, to an ongoing inability to satisfactorily solve specific problems, such as climate change or political gridlock. What these cases have in common is the collapse of collaboration and joint intentionality. In this sense, cultural failure is not merely a technical problem, an inability to identify and employ adequate means to a desired end. Instead, it involves a type of incoherence, an ability to understand which goals are salient and why these goals are worth pursuing (Jaeggi, 2018). What these sorts of failures manifest is the distinction between the moral norms and values specific to a particular culture and the good. This is the distinction between truth and warranted assertability (MacIntyre, 1985), between the judgments and actions that are accepted as valid in one's community and those judgments and actions that are actually valid. In other words, the experience of cultural failure provides the basis for a non-culturally relative conception of moral objectivity.

Second, the experience of cultural failure involves the breakdown of joint agency within specific social contexts but it also points to the existence of a broader, non-culturally specific, joint activity that potentially encompasses all persons. MacIntyre notes that within the sorts of cooperative activities highlighted by Tomasello (2020), individuals must learn from others about the nature of the goods that are at stake and about their relative importance in comparison with other goods. MacIntyre (1999, p. 141) calls this "political recognition," where this involves treating others as "someone whom it would be wrong to ignore or to exclude from political deliberation." Within this context, universal ethical norms make such learning possible. "Those universal and invariant requirements," MacIntyre (1994, p. 184) argues, "specify the preconditions for the kind of responsiveness by one human being to others which makes it possible for each to learn from the others' questioning." In other words, ethical norms sustain cooperative practices because they make learning possible, specifically, the kind of learning needed to overcome limitations of existing conceptions of the good within one's culture, to better attain the truth about the good.

As MacIntyre (1994, p. 184) says, "They are the preconditions of a kind of rational conversation in which no one need fear being victimized by others". Norms such as those associated with the virtues of honesty, courage, justice, benevolence, and temperance (MacIntyre, 2007) promote trust and give persons the assurance needed to learn from and teach other persons. Insofar as these norms are ignored, encounters with other persons will be rife with fear and opportunism, greatly limiting the possibilities for mutual learning. And because of the omnipresent possibility of cultural failure, and the need to learn from rival cultural traditions about the limits of one's own culture, ethical norms must extend beyond the bounds of one's specific culture. They must extend to all human beings, in order to facilitate "rational conversation... in achieving good and the good either within or between cultures" MacIntyre (1994, p. 184).

It is now possible to bring these threads together in order to explain MacIntyre's personalist moral psychology. As Tomasello (2020) argues, joint intentionally within cooperative activities facilitates a self-conscious sense of moral obligation. Agents understand themselves as integral elements of a group agenta "we"-that places binding obligations on its constituent members. Members understand themselves as bound by the norms structuring their shared activity and as responsible to other members because of their identification with the group agent. Cooperative activities extend beyond specific practices encompassing entire cultures understood as large-scale modes of joint agency. But cultures face the omnipresent potential for failure, involving incoherence and an inability to understand the point and purpose, that is the value, of the activities that members are engaged in. This potential for cultural failure enables persons to distinguish between the norms, goods, and values that are taken to be valid within their particular culture and those that are actually valid. In other words, the omnipresent potential for cultural failure gives rise to a sense of moral objectivity 
(MacIntyre, 1985), even if this is only the recognition that one's own culture has failed to attain moral truth and objectivity.

The drive toward objectivity or moral truth rather than cultural acceptability means that it is always necessary to learn from others, both from minority voices in one's own culture and from proponents of alternative cultural traditions (MacIntyre, 1994). This necessitates the political recognition of others as actual or potential partners in a shared inquiry concerning the good (MacIntyre, 1999, p. 141). But learning is only possible through an uncalculating adherence to ethical norms. Only by treating others as persons from whom it is always possible to learn something (MacIntyre, 1999), which means adhering to moral rules associated with virtues such as justice, courage, honesty, temperance, and benevolence is it possible to achieve one's own good (MacIntyre, 1994). Thus, one must treat other persons, both within and across cultures, as fellow participants in a rational conversation concerning the good, that is, in an all-encompassing activity of practical reasoning, in order to learn what is needed to attain objective moral truth. From this perspective, one is an integral element of a joint agent (Tomasello, 2020) that extends beyond any particular culture, encompassing all persons, thereby placing binding obligations on all human beings (MacIntyre, 1994, p. 185). From this perspective, persons can understand themselves as obligated by ethical norms because they are engaged in the shared activity of moral inquiry directed toward objective moral truth. As a person, I can only achieve my good insofar as I recognize that we must learn together about the good, where this "we" encompasses all persons, any of whom may teach me about the good (MacIntyre, 1999). Thus, MacIntyre's approach addresses Maritain's (1966) concern to avoid unilaterally subsuming persons within their communities or marginalizing communities in favor of individuals.

Before concluding, it is important to relate this account of MacIntyre's personalist moral psychology to his explicit discussions of relativism (see MacIntyre, 1977, 1988). First, it should be noted that two distinct questions arise whenever agents are faced with conflicting sets of moral norms. The first concerns the question of how they can navigate this sort of conflict so as to discriminate between and choose the set of norms that they have most reason to endorse. The second question concerns the way that agents have to think about moral norms, generally, so that this conflict between sets of norms does not undermine the very idea of normativity, the notion that norms are binding. These questions are not completely independent as a satisfactory answer to the first question is required for a fully satisfactory answer to the second, and vice-versa.

MacIntyre's (1977, 1988) explicit discussions of relativism largely focus on the first question. He argues that the experience of cultural failure or "epistemological crises," where communal norms lapse into incoherence (MacIntyre, 1977, p. 465) can be overcome through the construction of dramatic narratives that explain why specific sets of norms are inadequate and why this inadequacy only becomes visible by adopting a new and, therefore, superior perspective, the perspective of some rival community. The ability to truthfully construct this type of narrative not only provides individuals with a way of navigating radical conflict between sets of norms, specifically when current norms become increasingly incoherent but also provides confidence that were one's norms to lapse into this type of incoherence at some point in the future, one would be able to respond rationally to this problem.

The account of moral psychology articulated above focuses on the second question. Here the question is how persons must think about moral norms so that conflicting norms do not undermine the very idea of normativity. This is the problem facing Tomasello's (2020) account of moral psychology. Where his account provides key elements needed to think about moral psychology, especially the notions of joint intentionality, group agency, and self-conscious obligation, thereby shedding light on MacIntyre's approach, it does not address the problem of relativism because it centers upon culturally specific contexts of joint agency (Tomasello, 2020). MacIntyre's account goes beyond Tomasello's by viewing human beings as engaged in a mode of action that transcends specific cultures, the activity of moral inquiry, directed toward uncovering the truth about the human good (MacIntyre, 1994). In conjunction with Tomasello's account of joint agency, this explains how persons come to experience moral norms as genuinely binding in a manner that avoids the threat of relativism.

Thus, while MacIntyre's account of dramatic narratives sheds light on the problem of the bindingness of norms, by giving persons confidence that moral conflict is not intractable, this account also presupposes a personalist moral psychology since persons within a specific culture or community can only learn from others in radically different cultures, possibly deciding to adopt those radically different norms if they view those others as providing radically different answers to the very same question, the question about the good (MacIntyre, 1977, 1988, 1994). As MacIntyre (2007, p. 219) says, "the good life for man is the life spent in seeking for the good life for man". As such, it must be possible to view every culture as attempting to answer this question if one is to sustain a notion of political recognition (MacIntyre, 1999) that goes beyond specific cultures. Likewise, persons can only learn from others who are radically different insofar as they exercise virtues, avoiding violence, coercion, and manipulation (MacIntyre, 1994). This means that they must view the virtues, especially justice, not merely as norms that sustain their specific cultures or communities but rather as norms that enable them to learn from others no matter how different, norms that enable persons to address other persons as interlocutors within the shared activity of moral inquiry (MacIntyre, 1999), and possibly to adopt their perspective if it proves to be superior to their own (MacIntyre, 1977).

\section{CONCLUSION}

This article began by raising the question of whether MacIntyre's sociology of the virtues presupposes a personalist moral psychology. Because of its focus on the role of the virtues in sustaining social practices, MacIntyre's moral sociology has generated new opportunities for research in applied ethics and the social sciences. This work has combined theoretical and empirical perspectives that have shed new light on the 
importance of the virtues within organizations, professions, and other related social and institutional contexts. But taken as a purely functional claim, the notion that virtues are necessary to sustain social practices is problematic for two reasons. First, only a very minimal level of ethical commitment is required to actually "count" (Rawls, 1955) as participating in a practice. But this minimal level of ethical commitment is compatible with much vicious behavior between players, i.e., lying about moves made in previous games to confuse one's opponent.

Second, players may care more about success rather than excellence within practices. For instance, a doctor may use his medical expertise to perform lucrative operations that are somewhat harmful to patient health but which result in aesthetically pleasing changes for patients. By common opinion, this doctor is engaged in the practice of medicine, but he has clearly sacrificed patient health for financial gain. Thus, practices may operate for long periods of time, despite the absence of virtues amongst practitioners, when participants become focused more on success rather than excellence.

As such, a broader perspective is needed to understand the role of ethics within social practices. Tomasello's (2020) account of the moral psychology of obligation offers important insights that complement MacIntyre's (2007) account of the role of the virtues within social practices. Specifically, Tomasello argues that within cooperative contexts involving collective intentionality, participants develop a "we" perspective, that of a joint agent. From this perspective moral obligations are experienced as selfconsciously valid, as obligations that the agent must adhere to because of her identification with the joint agent. This account goes some way toward explaining the role of the virtues within practices but because it is indexed to specific cultures, which are viewed as specific contexts of joint intentionality (Tomasello, 2019) it faces the problem of relativism. Stated simply, when agents come to understand their experiences of moral obligation as resulting from their participation in a specific culture, they have reason to question the veracity of these experiences. Moral obligation may seem arbitrary, a cultural artifact to be ignored rather than something to be adhered to categorically. This limitation in Tomasello's (2020) account further illustrates key elements of MacIntyre's personalist moral psychology.

Thus, MacIntyre addresses this problem in two related ways. First, he notes the importance of cultural failure as a source of moral objectivity (MacIntyre, 1985), arguing that the experience

\section{REFERENCES}

Adams, R. M. (2006). A Theory of Virtue: Excellence in Being for the Good. New York: Oxford University Press. doi: 10.1093/acprof:oso/9780199207510.001. 0001

Anscombe, G. E. M. (1958). Modern moral philosophy. Philosophy. 33, 1-19. doi: $10.1017 /$ S0031819100037943

Beabout, G. R. (2012). Management as a domain-relative practice that requires and develops practical wisdom. Bus. Ethics Q. 22, 405-432. doi: $10.5840 /$ beq201222214

Beadle, R. (2013). Managerial work in a practice-embodying institution: The role of calling, the virtue of constancy. J Bus Ethics. 113, 679-690. doi: 10.1007/s10551-013-1678-2 of incoherence, lack of progress, or cultural breakdown (Lear, 2006) enables persons to distinguish between the moral norms and values recognized as valid within their culture at any given time from those that are objectively valid. Second, he argues that the potential for failure means that it is always possible to learn from others about the good, both those within one's cultural tradition and those in other traditions. MacIntyre (1999, p. 141) calls this political recognition, where this involves treating others as partners in a shared inquiry concerning the good, that is as persons from whom may have much to learn. But learning is only possible insofar as one observes a range of moral norms in one's interactions with others (MacIntyre, 1994), including especially the virtues.

Thus, beyond specific practices or cultures, all persons are potentially or actually engaged in a common joint activity, that of moral inquiry. This provides the ultimate point of reference for moral obligation. Agents experience a sense of moral obligation because of their membership in the community of persons engaged in moral inquiry, persons seeking the truth about the good. By forming a joint agent together with other persons, potentially all persons, in pursuit of moral truth (MacIntyre, 1985) moral obligation is experienced as self-consciously valid (Tomasello, 2020), in a manner that is not threatened by relativism. Accordingly, the virtues are needed to sustain social practices insofar as participants view them as important social contexts where it is always possible, and often necessary, to learn from others about the good. Thus, while Tomasello (2020) provides important insights into the way that moral obligations are generated in contexts of joint agency, MacIntyre explains how the experience of cultural breakdowns enables persons to view themselves as engaged in a transcultural mode of joint agency involving shared inquiry concerning the good.

\section{DATA AVAILABILITY STATEMENT}

The original contributions presented in the study are included in the article/supplementary material, further inquiries can be directed to the corresponding author.

\section{AUTHOR CONTRIBUTIONS}

The author confirms being the sole contributor of this work and has approved it for publication.
Beadle, R. (2017). MacIntyre's influence on business ethics. Handbook of Virtue Ethics in Business and Management. pp 59-67. doi: 10.1007/978-94-007-6510-8_2

Bernacchio, C. (2014). Macintyre's After virtue: A phenomenological reading. Cadernos do PET Filosofia. 5, 40-47. doi: 10.26694/cadpetfil.v5i9. 1697

Bernacchio, C. (2018). Networks of giving and receiving in an organizational context: Dependent rational animals and MacIntyrean business ethics. Bus. Ethics Q. 28, 377-400. doi: 10.1017/beq. 2018.1

Bernacchio, C. (2019). Pope Francis on conscience, gradualness, and discernment: Adapting Amoris Laetitia for business ethics. Bus. Ethics Q. 29, 437-460. doi: $10.1017 /$ beq. 2019.15 
Darwall, S. (2009). The Second-Person Standpoint: Morality, Respect, and Accountability. Cambridge, MA: Harvard University Press. doi: $10.2307 /$ j.ctv1bzfp0f

Holt, R. (2006). Principals and practice: Rhetoric and the moral character of managers. Human Relations. 59, 1659-80. doi: 10.1177/0018726706072867

Hursthouse, R. (1999). On Virtue Ethics. New York: Oxford University Press.

Jaeggi, R. (2018). On the Critique of Forms of Life. Cambridge, MA: Belknap Press. doi: $10.4159 / 9780674988712$

Kant,. I. (2012). Groundwork of the Metaphysics of Morals. Cambridge: Cambridge University Press. doi: 10.4324/9780203981948

Korsgaard, C. M. (1986). Aristotle and Kant on the source of value. Ethics. 96, 486-505. doi: 10.1086/292771

Lear, J. (2006). Radical hope: Ethics in the Face of Cultural Devastation. Cambridge, MA: Harvard University Press. doi: 10.4159/9780674040021

MacIntyre, A. (1977). Epistemological crises, dramatic narrative and the philosophy of science. The Monist. 60, 453-472. doi: 10.5840/monist197760427

MacIntyre, A. (1985). Relativism, power and philosophy. Proc. Am. Philos. Soc. 59: 1, 5-22. doi: 10.2307/3131644

MacIntyre, A. (1990). Three Rival Versions of Moral Enquiry: Encyclopaedia, Genealogy, and Tradition. Notre Dame, IN: University of Notre Dame Press.

MacIntyre, A. (1994). How can we learn what Veritatis Splendor has to teach? The Thomist: a Speculat. Q. Rev. 58:2, 171-195. doi: 10.1353/tho.1994.0026

MacIntyre, A. (1999). Dependent Rational Animals: Why Human Beings Need the Virtues. Chicago: Open Court Publishing.

MacIntyre, A. (2007). After Virtue, 3rd Edition. Notre Dame, IN: University of Notre Dame Press.

MacIntyre, A. (2016). Ethics in the Conflicts of Modernity: An Essay on Desire, Practical Reasoning, and Narrative. Cambridge: Cambridge University Press.

MacIntyre, A. C. (1988). Whose Justice? Which Rationality? Notre Dame, IN: University of Notre Dame Press.

Maritain, J. (1966). Person and Common Good. Notre Dame, IN: University of Notre Dame Press.

McDowell, J. (1978). Are moral requirements hypothetical imperatives? Proceedings of the Aristotelian Society, Supplementary Volumes 52, 13-42. doi: 10.1093/aristoteliansupp/52.1.13

McDowell, J. (1980). "The Role of Eudaimonia in Aristotle's Ethics" in Essays on Aristotle's Ethics, Rorty, A. O., eds. (University of California Press) p. 359-376. doi: 10.1525/9780520340985-022

Moore, G. (2012). Virtue in business: Alliance boots and an empirical exploration of MacIntyre's conceptual framework. Organ. Stud. 33:3, 363-387. doi: 10.1177/0170840611435599

Moore, G. (2017). On Virtue at Work: Ethics for Individuals, Managers, and Organizations. New York: Oxford University Press. doi: 10.1093/oso/9780198793441.001.0001

Rawls, J. (1955). Two concepts of rules. Philos. Rev. 64, 3-32. doi: 10.2307/2182230

Rawls, J. (1958). Justice as fairness. Philos. Rev. 67, 164-194. doi: 10.2307/2182612

Robson, A. (2015). Constancy and integrity:(un) measurable virtues? Bus. Ethics. 24, S115-S129. doi: 10.1111/beer.12103

Sandberg, J., and Tsoukas, H. (2011). Grasping the logic of practice: Theorizing through practical rationality. Acad. Manage. Rev. 36, 338-360. doi: 10.5465/AMR.2011.59330942

Scanlon, T. (2000). What We Owe to Each Other. Cambridge, MA: Belknap Press. doi: $10.2307 /$ j.ctv134vmrn
Sellman, D. (2000). Alasdair MacIntyre and the professional practice of nursing. Nurs. Philos. 1, 26-33. doi: 10.1046/j.1466-769x.2000.00 002.x

Shotter, J., and Tsoukas, H. (2014). In search of phronesis: Leadership and the art of judgment. Acad. Manag. Learn. Educ. 13, 224-243. doi: 10.5465/amle.2013.0201

Sinnicks, M. (2019). Moral education at work: On the scope of MacIntyre's concept of a practice. J. Bus. Ethics. 159, 105-118. doi: 10.1007/s10551-017-3753-6

Strawson, P. (1962). Freedom and resentment. Proc. Br. Acad. 48, 1-25.

Taylor, C. (1994). "Justice After Virtue," in After MacIntyre: Critical Perspectives on the Work of Alasdair MacIntyre, Horton, J., Mendus, S. (Notre Dame, IN: University of Notre Dame Press) p. 16-43.

Tenenbaum, S. (2019). Formalism and constitutivism in Kantian practical philosophy. Philos. Explor. 22, 163-176. doi: 10.1080/13869795.2019.1599053

Tomasello, M. (2014). A Natural History of Human Thinking. Cambridge, MA: Harvard University Press.

Tomasello, M. (2016). A Natural History of Human Morality. Cambridge, MA: Harvard University Press. doi: 10.4159/9780674915855

Tomasello, M. (2019). Becoming Human: A Theory of Ontogeny. Cambridge, MA: Belknap Press. doi: 10.4159/9780674988651

Tomasello, M. (2020). The moral psychology of obligation. Behav. Brain Sci. 43, 1-58. doi: 10.1017/S0140525X19001742

Tsoukas, H. (2018). Strategy and virtue: Developing strategy-as-practice through virtue ethics. Strateg. Organ. 16:3, 323-351. doi: 10.1177/1476127017733142

Weaver, G. R. (2006). Virtue in organizations: Moral identity as a foundation for moral agency. Organ. Stud. 27, 341-368. doi: 10.1177/0170840606062426

West, A. (2018). After virtue and accounting ethics. J. Bus. Ethics. 148:1, 21-36. doi: 10.1007/s10551-016-3018-9

Williams, B. (1981). "Persons, Character, and Morality," in Moral Luck (Cambridge: Cambridge University Press), 1-19. doi: 10.1017/CBO9781139165860.002

Williams, B. (1985). Ethics and the Limits of Philosophy. Cambridge, MA: Harvard University Press.

Williams, T. D., and Bengtsson, J. O. (2020). "Personalism," in The Stanford Encyclopedia of Philosophy, ed E. N. Zalta

Conflict of Interest: The author declares that the research was conducted in the absence of any commercial or financial relationships that could be construed as a potential conflict of interest.

Publisher's Note: All claims expressed in this article are solely those of the authors and do not necessarily represent those of their affiliated organizations, or those of the publisher, the editors and the reviewers. Any product that may be evaluated in this article, or claim that may be made by its manufacturer, is not guaranteed or endorsed by the publisher.

Copyright (c) 2022 Bernacchio. This is an open-access article distributed under the terms of the Creative Commons Attribution License (CC BY). The use, distribution or reproduction in other forums is permitted, provided the original author(s) and the copyright owner(s) are credited and that the original publication in this journal is cited, in accordance with accepted academic practice. No use, distribution or reproduction is permitted which does not comply with these terms. 